\title{
Academic Teamwork among Members of the National Researchers System in Tamaulipas
}

\author{
Teresa Guzman-Acuña ${ }^{1}$, Josefina Guzman-Acuña ${ }^{1}$, Ivan Sánchez-Rodriguez ${ }^{1}$ \\ ${ }^{1}$ School of Sciences, Education and Humanities, Autonomous University of Tamaulipas, Mexico \\ Correspondence: Teresa Guzman, School of Sciences, Education and Humanities, Autonomous University of \\ Tamaulipas, Cd. Victoria, Tamaulipas, México.
}

Received: April 26, 2016 Accepted: May 11, 2016 Online Published: May 31, 2016

doi:10.11114/jets.v4i9.1649 URL: http://dx.doi.org/10.11114/jets.v4i9.1649

\begin{abstract}
The objective of this article is to examine the participation of Mexican researchers in the state of Tamaulipas who are members of Mexico's National Researchers System (SNI) and are working in academic groups. The paper also seeks to understand their perceptions in relation to the usefulness of this structured System to their individual research projects and expertise. Based on a quantitative approach to research, a survey was answered by $46.19 \%$ of the total number of researchers in Tamaulipas who were affiliated to the SNI from December 2012 up to date. Data found indicated that an important minority (24\%) believed that the work dynamics of the research groups identified are not necessarily more useful than individual academic work to increase research productivity. Additionally, researcher participants pointed out several negative aspects of these structures of knowledge production.
\end{abstract}

Keywords: researchers, academic groups, individual work, higher education

\section{Introduction}

This article is drawn from a research project entitled "Conditions of Academic Productivity of Mexican researchers in Tamaulipas", which explores various dimensions of the work of these professionals: academic career, productivity, skills, expertise, approach to discipline, geographic flexibility, individual, group and networking job, physical working conditions, bureaucracy, funding, resources, time distribution, partnerships and impact.

This research project was born from the analysis of the current number of researchers affiliated to the National Research System (SNI). This analysis carried out in 2013 in 32 states of the country, identified that Tamaulipas is the state with the third lowest rate of researchers per 100,000 inhabitants, with 4.96 (Foro Consultivo Científico y Tecnológico, 2013). The main purpose of this analysis is to identify the causes of the low number of researchers and suggest the most appropriate and feasible strategies to increase the number of SNI researchers and improve the level of scientific and technological productivity.

This article, however, focuses on examining only the participation of researchers from Tamaulipas, who are SNI members in academic groups and on analyzing their views about the real utility of these structures in relation to their individual research work. The objective of this particular article is to obtain information to determine whether the participation of researchers in research groups is in fact an effective way to increase the scientific and technological production in Institutions of Higher Education (IHE). Additionally, the study seeks to explore: 1) the motivations or reasons the researchers are actually part of research groups; 2) the economic incentives granted to members of research groups/academic groups as one of the main reasons to join these structures; 3 ) the institutional pressure that has strongly influenced the decision of researchers to be part of a research group; 4) the researchers' reasons to prefer individual work over group work; 5) the activities collectively performed by researchers who are members of a research group, and 6) the importance given to collective research projects compared to individual research projects.

This study is intended to provide a first look at the perceptions and dynamics of SNI researchers in the state of Tamaulipas in relation to the collegial work and research groups. By collegial work, we refer to the scientific output produced by research groups or academic groups (according to the Professor Improvement Program, PROMEP). To research groups, we refer to the work teams integrated by researchers, technicians, and students develop following a specific research line defined and developed mainly in the schools, or departments of universities, higher education institutes and research centers. In theory, members of research groups should be actively involved in activities related to 
the production and dissemination of scientific knowledge and technological material. These activities include the designing and planning of research projects; finding funding for projects; searching for information/literature reviews; writing research reports; presenting findings in conferences/seminars; publishing research articles in indexed and peer-reviewed journals, etc.

In order to contextualize this research, in the following section titled "Framework", the main features of the SNI such as its main objectives, its operative procedures, the requirements scientists, technologists and researchers need to comply with to become affiliated to the System, the established categories used to classify SNI researchers, product research and academic activities upon which the candidates are evaluated. The Professor Improvement Program (PROMEP), which is another federal program that promotes research and training of "academic groups", is also described in this section.

Subsequently, the article provides a description of the methodology used to investigate the extent of the collegial work of researchers from the SNI in Tamaulipas. The results of the survey are presented immediately after the description of the methodology with the help of tables. Finally, the article provides some brief conclusions on the participation of SNI researchers in research groups and the use that is being given to research groups.

\section{Framework}

\subsection{National Research System (SNI)}

The National Research System is a program created by CONACYT to recognize the work of those engaged in producing scientific and technological knowledge in Mexico, thus contributing to the formation and consolidation of researchers at the highest level in an effort to increase the country's elements of culture, competitiveness, productivity, and social welfare.

Initially, the purpose of the SNI focused on two main aspects: reducing the country's brain drain and strengthening the quality of research and innovation in science and technology in Mexico. The SNI was inspired by the wage system based on the merit of the Higher Education Institutions of the United States, where each teacher's salary was based on their academic productivity (CONACYT, 2012a).

Currently, the SNI supports researchers from all scientific disciplines, which are divided into seven disciplinary areas: 1) Physics/Mathematics and Earth Sciences; 2) Biology and Chemistry; 3) Medicine and Health Sciences; 4) Humanities and Behavioral Sciences; 5) Social Sciences; 6) Biotechnology and Agricultural Sciences, and 7) Engineering.

The SNI rewards quality researchers through the "National Researcher", which is accompanied by an (non-taxable) economic stimulus that complements the remuneration.

To determine which researchers deserve recognition, SNI has a consultative commission (formed by members of the academic, scientific, and technological Mexican community) which considering standardized criteria and multifactorial measures, evaluates the academics and technologists who applied for SNI recognition.

\subsubsection{Evaluation Criteria for SNI Candidates}

As indicated in Article 41 of the existing regulation of the SNI, scientific and technological research that are considered by CONACYT to decide on the admission, readmission or renewal of SNI recognition and affiliation are: a) articles; $b$ ) books; c) book chapters; d) patents; e) technological developments; f) innovations, and g) technology transfers (CONACYT, 2012b).

Additionally, CONACYT takes into consideration the "Training of Scientists and Technologists" (CONACYT, 2012b), which is assessed through: a) the direction of theses completed to obtain postgraduate degrees; $b$ ) taught undergraduate and postgraduate courses, and c) training of future researchers and research groups. With regard to item "c", it is worth mentioning that although the SNI gives value to the training of potential researchers and research groups; it does not give much value to simply being a member of a research group. As mentioned in the Glossary Website CONACYT section (Note 1), "training of future researchers and research groups" is "a qualitative trait which refers only to the participation as leaders of a group in which team work is brought together for researchers, technicians, and students under a defined line of research, and which are trained to be independent researchers". As mentioned in that same section, this specific criterion is particularly taken into account for the researchers' promotion from level II to level III, and what the evaluation committees seek are elements that allow attribution, academic performance, scientific productivity, and group recognition of the leadership work performed by the researcher candidates. Complementary to the SNI applicant's is their participation in a) consultative commissions; b) in technical evaluation of projects supported by CONACYT Funds; c) in their work of scientific diffusion, d) in the link between their research and the public, private, and social sectors; e) in the participation in institutional development and e) creating, updating, and strengthening of undergraduate and postgraduate programs of study (CONACYT, 2012b). 


\subsubsection{SNI Categories}

The SNI uses three categories to recognize outstanding scientists and technologists, according to the quantity, quality, and relevance of its scientific and technological production (CONACYT, 2012b): I. National Researcher Candidate, II. National Researcher, with three levels and III. Emeritus National Researcher.

National Researcher Candidate is awarded to researchers who: a) meet the requirements of Article 33 of the SNI Regulation; 2) have a doctoral degree; 3) demonstrate that they have the necessary skills to conduct research, and 4) apply maximum 15 years since an undergraduate degree was obtained (Article 55 of the current regulationsCONACYT, 2012b).

According to Article 56 of the SNI Regulations, the National Research category Level 1 is granted to applicants who: 1) meet the requirements of Article 33 of the SNI Regulations; 2) have a doctoral degree; 3) have made original and quality research; 4) have directed and supervised undergraduate theses and doctoral dissertations; 5) have conducted teaching activities; 6) have been active in the divulgence of science; 7) have been promoted and tenured; and 8) have performed any of the activities listed in Article 42 (described above) of the SNI Regulations (CONACYT, 2012b).

Level 2 of the National Research Category is granted to applicants who meet the requirements of Level 1 in addition to the following 1) have produced individually or in groups, original research, that is scientifically or technologically recognized, measurable, consistent and which has contributed to the consolidation of a research line; 2) have directed postgraduate theses, and 3) have contributed to the formation of high-level human resources (CONACYT, 2012b).

The third category of the National Research Level is authorized for applicants who meet the requirements of Level 2 plus: 1) have conducted research that represents an important scientific or technological contribution to the generation and application of knowledge to the field of expertise; 2) have developed outstanding leadership activities in the national scientific or technological community; 3 ) have both national and international recognition for their scientific or technological activities, and 4) have an outstanding line of work in the formation of high-level human resources for the country (CONACYT, 2012b).

Finally, according to Article 57 of the regulations, the category of Emeritus National Researcher is granted to researchers who request the distinction and who: 1) have a minimum age of 65 years; 2) have minimum 15 years with the distinction of National Researcher Level 3;3) demonstrate an exceptional academic record in Mexico, with a fundamental contribution to the generation of knowledge and scientific or technological development; contribute to the generations of new researchers through a transcendent leadership role and international prestige, and 4) is recommended to receive this distinction by at least nine members of the Judging Commission related to the area of expertise of the candidate.

\subsection{Professor Improvement Program (PROMEP)}

Another federal program that has contributed significantly to increase the production of scientific and technological knowledge, emphasizing the training of researchers and research groups in Mexico, is the Professor Improvement Program (PROMEP).

PROMEP is a federal program that has been operating since 1996 to improve the level of education, academic profile, scientific and technological production, and the collegiate work organization of full-time faculty professors of public higher education institutions of the country. Designed by the Ministry of Education (SEP) (Note 2) through its Department of Higher Education (SES) (Note 3) and involving the assistance of the National Association of Universities and Institutions of Higher Education, ANUIES (Note 4) as well as the CONACYT, PROMEP has four main objectives as outlined below:

1. Increase the proportion of Full-time faculty professors (FP) in higher education institutions in which it operates in relation to the overall staff (including full- and part-time professors).

2. Increase the proportion of FPs that has an appropriate level of academic studies to perform activities at a university or an institution of higher education, for instance, a PhD.

3. Increase the proportion of FPs with a "Desirable Profile". In other words, professors with an appropriate level of studies that develops competently and productively in a balanced manner the four core academic functions (as considered by PROMEP): Teaching; Researching; Tutoring, and Academic Management.

4. Improve the organization and academic performance of FPs through the creation of "academic groups"; that is, multifunctional groups formed by FPs working the same area or areas of knowledge, and which share one or several lines of investigation. The previous with the purpose of working together to develop the basic functions of higher education institutions: a) increase the scientific and technological production; b) develop human resources, and c) strengthen the curriculum and academic planning (SEP, 2006). 
In 1996 and during the first 6 years of operation, PROMEP focused on supporting professors in state public universities; but in 2002, it began to support other subsystems of higher education such as state public universities with mixed funding, polytechnic universities and technological universities; then in 2008, it integrated its support to federal institutes of technology. In 2009 it expanded support to the teacher schools of the country (Normal Schools as named in Spanish), and in 2010 it included the decentralized technological institutes and the intercultural universities (SEP, 2013).

PROMEP implement a system to identify, certify, acknowledge and reward economically FPs with a "Desirable Profile" which takes into account the scientific and/or technological production. Research products accepted by PROMEP, to evaluate the scientific and/or technological production of a FP, is very similar to the list of products accepted by the CONACYT to evaluate SNI candidates. The evaluation of candidates for the "Desirable Profile" is also done in pairs and carried out by consultative commissions, which are grouped according areas of expertise. The Desirable Profile recognition currently is valid for a 3-year period (Note 5).

One of the strategies implemented by PROMEP to ensure that FPs would join or form an academic group was to condition the assignment of financial resources for research projects to FPs who belong to an academic group, as done so by the CONACYT. Thus, researchers need to be part of an academic group in order to receive PROMEP or CONACYT financial support.

To ensure that academic groups develop research activities, PROMEP offered resources to academic groups to carry out their research projects that could cover the costs associated with these (purchase of materials and research equipment, conducting in research stays, attendance at conferences and symposia, publication costs) and to establish networks with other academic groups.

The emphasis of the SEP in the adoption of the "new" academic profile and training of academic groups regulations took most FPs of higher education institutions by surprise. Previous to this "new policy, only a few professors had conducted research or formed part of a research group.

\subsubsection{Advance in the Creation of Academic Groups}

PROMEP created the first national database of academic groups in 2000, and in 2001 created a system for classifying those groups according to their level of consolidation which considered factors such as: 1) the level of education and academic profile of its members (which can be only FPs); 2) their academic and scientific production; 3) participation in networks of knowledge and research with other research groups, and 4) participation in institutional academic activities (SEP, 2006). The three types of academic groups recognized by PROMEP are listed below from most to least relevant:

Consolidated academic group. This type of group is characterized by traits such as 1) most of its members have a doctoral degree, 2) a "Desirable Profile" certification, 3) a SNI recognition, 4) they conduct research on a regular basis and publish it in high-impact, peer-reviewed, and indexed journals, 5) they show an intense academic activity (through frequent participation in conferences, seminars, discussion panels, and workshops), and 6) have established connections with other academic groups in Mexico and abroad.

Academic group in consolidation. More than half of the members of this group have a doctoral degree, and at least half of them have earned the "Desirable Profile"; its research is produced as a group/team, and it establishes communication with other academic groups.

Academic group in training. Less than half of its members have a doctoral degree or the "Desirable Profile"; has defined its line of generation and application of knowledge but has not produced significant research results or products, and it has established contact with related academic groups.

In 2001, the groups that did not meet the requirements for recognition as academic groups therefore they were classified as "disciplinary groups". However, in 2003, these groups began to be considered as academic groups in training (ANUIES, 2006).

To understand the evolution of academic groups in IHE supported by PROMEP, the table below depicts the evolution of the number of academic groups that have existed in the state public universities. The table shows the evolution of years from 2002, 2008 and 2012. 
Table 1. Evolution of the number of academic groups: total number and by category (2002-2012)

\begin{tabular}{cccccccc}
\hline & & \multicolumn{2}{c}{ In training } & \multicolumn{2}{c}{ In Consolidation } & \multicolumn{2}{c}{ Consolidated } \\
\cline { 3 - 8 } Year & Total & $\mathrm{N}$ & $\%$ & $\mathrm{~N}$ & $\%$ & $\mathrm{~N}$ & $\%$ \\
$\mathbf{2 0 0 2}$ & 2,359 & 2,155 & 91.35 & 170 & 7.20 & 34 & 1.44 \\
$\mathbf{2 0 0 8}$ & 2,903 & 1,988 & 68.48 & 617 & 21.25 & 298 & 10.26 \\
$\mathbf{2 0 1 2}$ & 2,869 & 1,260 & 43.91 & 955 & 33.28 & 654 & 22.79 \\
\hline
\end{tabular}

Source: Creation of the authors with information from the following sources: 2002 data taken from the Asociación Nacional de Instituciones de Educación Superior (National Association of Institutions of Higher Education, ANUIES) (2006, p. 105), from 2008 from the Subsecretaría of Educación Superior (Subministry of Higher Education, SES) (2009), and from 2012 from the Secretaría de Educación Pública.

As we can see from the Table 1, if we focus on the total number of academic groups regardless of their level of consolidation, it seems there was a breakthrough in the creation and maintenance of the academic groups from 2002 to 2008 , when the number increased from 2,359 to 2,903. However, the total number of academic groups recognized by PROMEP decreased slightly (only 1.17\%) in 2012, compared to 2008, going from 2,903 to 2,869.

If the focus of analysis is the consolidated academic groups, the development has not grown as much as desired. These groups are the only ones who really carry out all the tasks and produce an important and coherent number of research products. The number of consolidated academic groups increased from 34 in 2002, to 298 in 2008, and to 654 in 2012. As noted, the increase has been constant but very low considering the large number of universities where these groups are spread (39) out. On average, in 2012, there were 17 consolidated academic groups in each state public university supported by PROMEP. This is a very low number if it is considered that each higher education institution has many schools with various undergraduate and postgraduate programs offered, and each of them need a consolidated academic group to function properly.

\section{Method}

This study is based on a quantitative approach to data collection and analysis. SNI affiliated researchers working in the State of Tamaulipas answered a survey (which was briefly described in the Introduction section of this article.) to fulfill the purpose of this paper. This article focuses on the analysis of a small part of researchers who are participants of a larger study on Mexican academics in the state of Tamaulipas. The survey took into account the total number of researchers, 171, working in IHE of the state who were SNI members in December 2012, according to the report published by CONACYT (2013b).

The survey consisted of a questionnaire of 89 items divided into 16 sections that explored the dimensions outlined in Section 1 of this paper. In order to minimize bias in responses and make the answering process easier and faster, multiple choice and closed questions were included. The questionnaire was delivered in print and digital format on an online platform.

On November 25, 171 SNI researchers were contacted by e-mail. The electronic addresses of the researchers were obtained through the SNI database. The e-mail sent invited each of these researchers to participate in the project and provided them with a link that leads to the online questionnaire. Fifteen days after the mail was sent, the researchers who had not answered the online questionnaire were visited to motivate them to answer the questionnaire in their workplaces. This time, the instrument was offered in printed form. In the end, 79 researchers $(46.19 \%)$ of the total population of SNI researchers in Tamaulipas in December 2012 (171) answered the questionnaire.

This paper focuses on the analysis of the responses to the questions that focus on attitudes towards teamwork, academic groups, and research groups as follows:

1. Are you part of a research or an academic group? What type?

2. Are the dynamics of research groups/academic groups better than those of individual work to increase the scientific and academic production in IHE and research centers?

3. Are economic incentives major reasons why you are part of a research group?

4. Is belonging to research or academic group motivated by institutional pressure?

5. If you are not integrated to a research group or academic group, what are the reasons?

6. If you belong to a research group or an academic group, what are the research activities that are carried out collectively?

7. What is the importance you give to research group projects compared to individual/personal projects? 


\section{Results}

This section presents the survey's main results regarding teamwork, academic and research groups. All tables presented below were prepared by the author and contain data obtained through the previously mentioned survey.

\subsection{Main Features of the Final Sample of Researchers}

As shown on Table 2, the final sample of researchers SNI from Tamaulipas (79) is diverse in terms of gender (although the vast majority are men), age, marital status, levels of education in which courses are taught, IHE affiliation, time working at the IHE, SNI category/level (although there was no category III or Researcher Emeritus), and amount of time affiliated to the SNI. The sample is also diverse in terms of area of expertise (see Table 3).

Table 2. Main features of the sample of researchers

\begin{tabular}{|c|c|c|}
\hline & Masculine & $71 \%$ \\
\hline Gender & Feminine & $29 \%$ \\
\hline \multirow[t]{4}{*}{ Age (years) } & $25-35$ & $23 \%$ \\
\hline & $36-45$ & $38 \%$ \\
\hline & $46-55$ & $29 \%$ \\
\hline & 56 and over & $10 \%$ \\
\hline \multirow[t]{5}{*}{ Civil status } & Single & $28 \%$ \\
\hline & Married & $65 \%$ \\
\hline & Divorced & $4 \%$ \\
\hline & Widower (Widow) & $1 \%$ \\
\hline & Consensual union & $2 \%$ \\
\hline \multirow[t]{2}{*}{ Level of studies } & Master degree & $0 \%$ \\
\hline & Doctoral degree & $100 \%$ \\
\hline \multirow{2}{*}{ IHE work category } & Full-time professor & $97 \%$ \\
\hline & Part-time professor & $3 \%$ \\
\hline \multirow{4}{*}{$\begin{array}{l}\text { Levels of education of taught } \\
\text { courses }\end{array}$} & Undergraduate level & \\
\hline & Master level & $72 \%$ \\
\hline & Doctoral level & $81 \%$ \\
\hline & & $52 \%$ \\
\hline \multirow[t]{5}{*}{ Amount of time at IHE } & 1 year or less & $8 \%$ \\
\hline & $1-5$ years & $29 \%$ \\
\hline & $6-10$ years & $14 \%$ \\
\hline & $11-15$ years & $19 \%$ \\
\hline & 16 years or more & $30 \%$ \\
\hline \multirow[t]{3}{*}{ SNI category } & Candidate & $37 \%$ \\
\hline & Level 1 & $58 \%$ \\
\hline & Level 2 & $5 \%$ \\
\hline \multirow[t]{5}{*}{ Time affiliated to SNI } & 1 year or less & $16 \%$ \\
\hline & $1-3$ years & $35 \%$ \\
\hline & 4-6 years & $19 \%$ \\
\hline & 7-9 years & $13 \%$ \\
\hline & 10 years or more & $17 \%$ \\
\hline
\end{tabular}

Table 3. Researchers' Area of Work

\begin{tabular}{ll}
\hline Physical and Mathematical Sciences, and Earth Sciences & $10.1 \%$ \\
Biology and Chemistry & $5.1 \%$ \\
Medicine and Health Sciences & $1.3 \%$ \\
Humanities and Behavioral Sciences & $7.6 \%$ \\
Social Sciences & $13.9 \%$ \\
Biotechnology and Agricultural Sciences & $21.5 \%$ \\
Engineering & $34.2 \%$ \\
Source: Authors' elaboration based on survey data. & \\
\hline
\end{tabular}

As can be seen in Table 4, the researchers who participated in the survey came from nine IHE. It is important to point out that all these institutions can benefit from CONACYT programs and academic staff can apply to be part of the SNI. From this list, PROMEP works in agreement with all the institutions except the first four listed institutions. 
Table 4. Institution of researchers' affiliation

$\begin{array}{lc}\text { 1.Center of Investigation in Applied Science and Advanced Technology of the National Polytechnic } & 11.39 \%(9) \\ \text { Institute (IPN), Altamira Campus (CICATA) } & \\ \text { 2.Center of Investigation and Advanced Studies of the IPN (CINVESTAV-IPN), Ciudad Victoria, } & 8.86 \%(7) \\ \text { Tamaulipas } & 1.26 \%(1) \\ \text { 3.Institute of Higher Studies of Tamaulipas } & 13.92 \%(11) \\ \text { 4.Instituto Nacional de Investigaciones Forestales, Agrícolas y Agropecuarias (National Institute of } & \\ \text { Forestry and Agricultural and Animal Husbandry Investigations, INIFAP), Northeastern Regional } & 20.25 \%(16) \\ \text { Investigation Center (Tamaulipas) } & 5.06 \%(4) \\ \text { 5.Technological Institute of Ciudad Madero (Tamaulipas) (DEGEST) } & 32.91 \%(26) \\ \text { 6.Technological Institute of Ciudad Victoria (DEGEST) } & \\ \text { 7.Autonomous University of Tamaulipas (UAT) } & \\ \text { Schools/Faculties located in Ciudad Victoria 8.86\% (7) } & 5.06 \%(4) \\ \text { Schools/Faculties located in Tampico-Madero 7.59\% (6) } & 1.26 \%(1) \\ \text { Schools/Faculties located in Nuevo Laredo 1.26\% (1) } & \\ \text { Schools/Faculties located in Reynosa 7.59\% (6) } & \\ \text { Schools/Faculties located in Ciudad Mante 3.79\% (3) } & \\ \text { Schools/Faculties located in Matamoros 3.79\% (3) } & \text { 8.Polytechnic University of Victoria (UPV) } \\ \text { 9.Polytechnic University of Altamira (UPA) } & \end{array}$
Source: Authors' elaboration on survey data.

In relation to the time dedicated to research, more than one third of the sample, 37\%, spend 21 to 30 hours a week to doing research, $21 \%$ spend less than 20 hours, $17 \%$ between 31 and 40 hours and $16 \%$ over 41 hours. These numbers indicate that the vast majority of researchers, nearly four-fifths, dedicate more than half of their weekly working hours to research, while $16 \%$ all of their time. However, it is important to mention that the number of hours spent on research activities are determined by the IHE to which the researcher is affiliated, as they decide how many hours assign to full-time academic research, teaching, tutoring and academic management.

\subsection{Affiliation to Research Groups}

Surveyed SNI researchers, $93.68 \%$ stated to be part of a research group. Interestingly, these researchers belonging to a research group, $62.16 \%$ belong to an "academic group", which are the working and research groups promoted and recognized by PROMEP in most of the Mexico's public IHE. It is also important to note that $90.19 \%$ of all SNI researchers coming from IHE and supported by PROMEP (64.55\% of the sample of respondents) belonged to an academic group. This number suggests that the introduction of the PROMEP program has had a strong impact on the forms of academic and collegial organization of SNI researchers who are part of the IHE network.

SNI researchers belonging to an academic group, $71.73 \%$ belonged to a consolidated academic group, while the rest belonged to an academic group in consolidation (28.26\%). This means that none of the researchers was part of an academic group in training.

On the other hand, $100 \%$ of the SNI researchers who participated in this study and belong to IHE/ Research Centers not benefitted by PROMEP were part of a research group.

The fact that only $6.32 \%$ of the researchers are not part of any research group suggests that the vast majority of researchers prefer or find more convenient to work collegially than individually

\subsection{Utility of Research Groups/Academic Groups to Increase Scientific and Academic Production in IHE}

The majority of researchers, $76 \%$, believe that the dynamics of research groups are better than the dynamics of individual research to increase scientific and academic production in IHE and Research Centers. However, a significant minority of respondent researchers, $24 \%$, disagrees and believes that the work of individual research is more effective. Some researchers also mentioned that research groups actually induce researchers to work less and that many were only part of these groups because their dynamics allows them to more easily meet the requirements of the SNI in relation to the number of research products required each year.

\subsection{Influence of Economic Incentives in Research Group Decision-making}

The vast majority of researchers, $87 \%$, agree that one of the most important reasons why they were part of a research group were the benefits and economic incentives/bonuses that are provided to members. As previously mentioned, many of the IHE served by PROMEP give annual bonuses or incentives to their teaching/academic staff and these incentives are increased if the professors are part of an academic group, and even more if this group is consolidated. Many of the researchers who agree that financial incentives were a motivator to remain in research groups also mentioned that another economic incentive was the fact that there are more probabilities of obtaining financial support for group research projects than for individual ones. 


\subsection{Influence of Institutional Pressure in the Decision to be Part of a Research Group}

An important percentage of SNI affiliated participants who are part of a research or academic group, 54\%, stated that their integration into a research group itself had been motivated by pressure exerted on them by their IHE. It is important to note that $91.11 \%$ of all researchers belonging to a recognized academic group by PROMEP selected this option as one of the reasons to be part of such structure. This is understandable since all the IHE supported by PROMEP are at the same time pressured by the Ministry of Education (SEP) to build and strengthen academic groups and collaboration networks.

\subsection{Reasons for Not Participating in Research Groups/Academic Groups}

Researchers who were not part of any academic group ( $06.32 \%$ of the sample) generally indicated two main reasons of doing research individually at the time of the study; 1) they believed that research groups limit the autonomy of the researchers and sacrifice their personal lines of research, and 2) they find it difficult to work and reach agreements with other researchers at the same level.

\subsection{Activities undertaken Collectively by Researchers Members of Academic Groups}

According to the survey, the vast majority of researchers who are part of a research group participate actively and as a group in each of the main activities related to the production and dissemination of scientific knowledge. As shown in Table 5, all researchers were involved in the production of reports/research papers; however, not all participated in other activities related to the development and dissemination of research products such as following procedures for publishing research papers. The design and planning of research projects and seeking information/literature review is conducted by more than $90 \%$ of researchers who are part of a research group.

The activity performed by the lowest percentage of researchers is that of "procedures for the publication of papers in journals", which appears to be assigned only to some members of the research group.

Table 5. Related research activities are carried collectivity by researchers $(n=74)$

\begin{tabular}{ll}
\hline Activity & $\%$ of researchers \\
\hline Production of reports/research papers & 100 \\
Design and planning of research projects & 97 \\
Finding information/literature review & 94 \\
Procedures for funding & 68 \\
Presentation of progress and results at conferences/seminars & 65 \\
Procedures for the publication of papers in refereed journals & 61 \\
\hline
\end{tabular}

Source: Creation by authors based on survey data

\subsection{Priority Given to Research Collective Tasks Compared to Individual Research}

In relation to the importance given to the activities of collective research compared to individual projects, $73 \%$ of the researchers who were part of a research group at the time of the survey indicated that they give equal effort and importance to personal and group projects, suggesting that researchers really take seriously their obligations within these structures (see Table 6). Only 7\% admitted to put more effort to personal projects. Researchers who gave this response indicated that personal projects are more beneficial for their development as researchers.

On the other hand, $16 \%$ of the sample tends to give more importance to group projects. Some of the researchers who selected this option stated they gave priority to collective projects because these projects these were generally broader and had a bigger budget. Only $4 \%$ of the sample clearly admitted that the importance given to personal and group projects depends on funding or remuneration involved in these projects.

Table 6. Importance given to collective and individual projects by members of a research group at the time of the survey

$\begin{array}{ll}\text { Equal weight is given to both collaborative research projects as individual } & 73 \% \\ \text { Priority is given to collective research projects } & 16 \% \\ \text { Priority is given to individual research projects } & 7 \% \\ \text { Priority is given to collective and individual research tasks depending on funding or remuneration } & 4 \% \\ \text { involved in these projects } & \end{array}$

Source: Authors' elaboration based on survey data

\section{Discussion and Conclusions}

The results of this study suggest that the vast majority of SNI researchers from Tamaulipas, Mexico (over 90\%) are part of a research group or a collegial structure, such as academic groups, where collective research is a fundamental part. 
An important amount of researchers, 76\%, believed that research groups facilitate and increase the scientific and academic production in IHE and research centers. However, a significant minority (24\%) strongly believed that the dynamics of a research group does not necessarily result in a greater number of research products, but may simply make it easier for researchers to meet the requirements in relation to the number of research products required each year to obtain and maintain affiliation to the SNI.

In addition, there are factors that are not directly related to scientific production that motivate most researchers to join a research group such as the benefits and economic incentives/bonuses awarded to members and the constant pressure exerted on them for their IHE (recognized by $87 \%$ and $54 \%$ of researchers who were part of a research group). This would suggest that, in many cases, the formation and operation of research groups in Tamaulipas is motivated to some extent by monetary interests and institutional pressure, and not necessarily academic interests or passions.

The few researchers who at the time of the survey were carrying out research projects individually (6.32\% of the sample) had a very different perception of research groups. They generally consider research groups limit the autonomy of researchers, may force them to sacrifice their personal lines of inquiry, and stated that collaborative work is not always easy or pleasant.

As for the activities carried out collectively by researchers members of academic groups, the study found that, the vast majority of the researchers are actively involved individually and collectively in each of the main activities related to the production and dissemination of scientific knowledge. On the other hand, $73 \%$ of researchers who were part of a research group at the time of the survey indicated that they put the same effort and importance to personal and group projects, suggesting that researchers take seriously their obligations within these structures.

Finally, it is important to note that this is a first approach to the perceptions of SNI affiliated researchers, who in theory are the most productive researchers in México, of the real value of work in research groups compared to individual research. What has become clear is that it is necessary to further examine whether to promote the creation of research and academic groups is the right strategy to try to increase the scientific production at universities and IHE for it has become clear that a percentage of SNI researchers perceive negative aspects in the dynamics of these structures.

\section{References}

ANUIES (2006). Consolidación y avance de la educación en México. Elementos de diagnóstico y propuestas. México: ANUIES.

CONACYT (2012a). El Sistema Nacional de Investigadores. Retrieved June $12, \quad 2013$ from http://www.conacyt.gob.mx/sni/Paginas/default.aspx.

CONACYT (2012b). ACUERDO por el que se reforman diversos artículos del Reglamento del Sistema Nacional de Investigadores. SEGUNDA SECCIÓN, PODER EJECUTIVO, CONSEJO NACIONAL DE CIENCIA Y TECNOLOGÍA. DIARIO OFICIAL (Segunda Sección). México. Retrieved August, 2013 from http://www.conacyt.gob.mx/SNI/Documents/Reglamento_2013.pdf

CONACYT (2013a). El Consejo Nacional de Ciencia y Tecnología. Retrieved June 12, 2013 from http://www.conacyt.gob.mx/ElConacyt/Paginas/default.aspx

CONACYT (2013b). LA ACTIVIDAD DEL CONACYT POR ENTIDAD FEDERATIVA 2012. Tamaulipas. México: CONACYT. Retrieved July 7, 2013 from http://www.siicyt.gob.mx/siicyt/docs/ActConacytEstados/2012/Tamaulipas(2012).pdf

Foro Consultivo científico y Tecnológico A.C. (2013). Sistema Nacional de Investigadores. Retrieved November 24, 2013 from

http://www.foroconsultivo.org.mx/documentos/acertadistico/conacyt/sistema_nacional_de_investigadores.pdf

SEP (2006). Un primer análisis de su operación e impactos en el proceso de fortalecimiento académico de las universidades públicas. México: Autor. Retrieved September 7, 2013 from

http://promep.sep.gob.mx/infgene/PROMEPanalisis1.pdf

SEP (2013). Taller fondos extraordinarios. UPES y UPEAS 2013.

SES (2009). Evaluación de los programas sociales apoyados con subsidios y transferencias. Primer Trimestre 2009. Retrieved September 7, 2013 from http://promep.sep.gob.mx/TRIMESTRALES/1er\%20Trimestre\%202009/1ertrimestre2009PROMEP.pdf 


\section{Notes}

Note 1. http://www.conacyt.gob.mx/SNI/Paginas/SNI_Glosario.aspx).

Note 2. Created in 1921.

Note 3. Formerly known as the Subsecretaría de Educación Superior e Investigación Científica (Subministry of Higher Education and Scientific Research, SESIC).

Note 4. ANUIES is a Non-governmental organization (NGO) created in 1958 to improve and standardize the faculty, research, and cultural programs at public and private Institutions of Higher Education (IHE) of the country (additional information is available at the official Website of the Association: (http://www.anuies.mx/).

Note 5. More information on criteria for awarding "desirable profile" recognition is available at the PROMEP Website (http://promep.sep.gob.mx/).

This work is licensed under a Creative Commons Attribution 3.0 License. 